\title{
Privacy, Informed Consent, and Participant Observation
}

Zahle, Julie

Published in:

Perspectives on Science

DOI:

10.1162/POSC_a_00250

Publication date:

2017

Document version

Peer reviewed version

Citation for published version (APA):

Zahle, J. (2017). Privacy, Informed Consent, and Participant Observation. Perspectives on Science, 25(4), 465487. https://doi.org/10.1162/POSC_a_00250 


\title{
Privacy, Informed Consent, and Participant Observation
}

Julie Zahle - juliezahle@gmail.com

\begin{abstract}
In this paper, I begin by detailing how social researchers may use informed consent to protect the situational and informational privacy of those they study while gathering data by way of the method of participant observation. Next, I argue that the principle of informed consent should not be regarded as an absolute demand: under specified conditions, it is acceptable to make an exception to the principle. Finally, I demonstrate that the employment of informed consent does not suffice to protect individuals' privacy: social researchers must take a number of additional measures to prevent privacy invasions from occurring.
\end{abstract}

\section{Introduction}

In the literature on social research, adherence to the principle of informed consent is sometimes recommended on the ground that the privacy of those being studied is hereby protected (see, e.g., Kelman 1977; Sieber 1992, p. 9; Hammersley and Traianou 2012, p. 114ff). The principle has it that before becoming part of a study, a competent individual must receive information about its purpose, use, etc., and on this basis freely agree to participate. Joan Sieber motivates the employment of informed consent as a way to safeguard research participants' privacy as follows: "A research experience regarded by some as a delightful opportunity for self-disclosure could constitute an unbearable invasion of privacy for others. Informed consent is an important way to respect these individual differences [...] One who considers a given research procedure an invasion of privacy can simply decline to participate" (Sieber, 1992, p. 49).

In this paper, I examine in depth the proposal that social researchers should abide by the principle of informed consent in order to protect the privacy of those they study. More precisely, I consider this suggestion in the context of data generation by way of participant observation - a qualitative method that is widely used in the social sciences and humanities. Surprisingly, no comprehensive analysis along these lines has been offered so far whether by philosophers or social researchers.

I start by introducing the method of participant observation. Next, I argue that there are two main ways in which a social researcher may intrude on individuals' privacy when generating data by way of this method: she may invade research participants' situational and informational privacy. On this basis, I present the principle of informed consent and show how to specify its conditions of application in order to tailor it to the protection of individuals' situational and informational privacy. In the remainder of the paper, I take it that a participant observer should indeed make use of informed consent so as to safeguard research participants' privacy. This contention raises two issues. The first is whether the principle of informed consent should be embraced as an absolute principle, that is, a principle without exceptions. I show that when certain conditions are met, the participant observer may make an exception to the principle and hereby set to a side the privacy protection that the principle offers. The other issue is whether the employment of informed consent is sufficient to protect research participants' situational and informational privacy. I draw attention to three circumstances in which the participant observer needs to take further measures in order to prevent privacy invasions from occurring while she generates her data. Moreover, I discuss what these supplementary measures are.

In the literature on social research, two further ways in which to protect research participants' privacy are commonly mentioned too. Both of them deal with different aspects of treating collected data 
confidentially. One strategy is to keep the data from others: the social researcher should store her data securely such that unauthorized access to them is prevented. Also, she should not grant others access to the data without the research participants' permission (see, e.g., Kelman 1977, p. 173; Hammersley and Traianou 2012, p. 123ff). The other strategy is anonymization: the social researcher should anonymize her data by removing information that may enable others to identify research participants. The data may be anonymized before storage or, at the very least, when they are referred to in reports of the research findings (see, e.g., Kelman 1977, p. 173; Fluehr-Lobban 1994, p. 4; Christians 2011, p. 66; DeWalt and DeWalt 2011, pp. 218-219;; Hammersley and Traianou 2012, p. 126ff). In the following, I do not further discuss these additional ways in which to safeguard research participants' privacy. I simply assume that the participant observer employs both of them too. Accordingly, when I later argue that informed consent does not suffice to protect individuals' situational and informational privacy, I do not have in mind that the social researcher must also treat her collected data confidentially in the two ways just outlined.

\section{Participant Observation}

Participant observation is a data generating method that is widely used in the social sciences and the humanities. ${ }^{1}$ There are two components to the method: participation and observation. The participatory component requires the social researcher to take part in the ways of life she studies. There are different degrees to which the social researcher may participate. For instance, she may do so in the weaker sense of simply hanging around or in the stronger sense of engaging actively in the activities under study. ${ }^{2}$ Whatever her degree of participation, the researcher should try to affect the ways of life she studies as little as possible since her immediate aim is not to alter, but to learn about them.

The observational component of the method requires the participating researcher to observe, in the broad sense of noticing, what goes on. It is widely held that participant observation should be carried out over an extended period of time. Earlier on in anthropology for example, it was standard that the researcher stayed with the individuals she studied for at least a year. Today, studies of a shorter duration are also regarded as acceptable.

The point of carrying out participant observation was famously described by Bronislaw Malinowski who is regarded as one of the main founders of the method. Participant observation, he states, allows the social researcher "to grasp the native's point of view, his relation to life, to realize his vision of his world" (Malinowski 1922, p. 25 - italics in original). Today this is still regarded as the primary aim - and strength - of the method. Accordingly, the research participants' views, perspectives, experiences, etc. are always the starting point of analysis. At the same time, the social researcher may well go beyond, and even challenge, these views, perspectives, etc. in her account of the research participants' ways of life.

\section{Participant Observation and Privacy Invasion}

When carrying out participant observation, there are at least two main ways in which the social researcher may violate people's privacy. In what follows, I outline both types of privacy invasion while briefly placing the account in the context of general discussions of privacy. I should stress that I do not mean to imply that social researchers commonly breach people's privacy in the ways suggested and exemplified below. The sole purpose

\footnotetext{
'The following characterization draws on various handbooks on the use of participant observation including Agar (1980); Spradley (1980); Jorgensen (1989); Bailey (1996); Hammersley and Atkinson (2003); DeWalt \& DeWalt (2011). For similar brief outlines of participant observation, see Zahle (2012; 2016).

${ }^{2}$ For classifications of the different extents to which a participant observer may take part in the ways of life she studies, see, e.g., Gold (1969), Spradley (1980, p. 58ff); Nelson (1986, p. 8ff).
} 
of the discussion is to articulate how the use of participation observation may possibly result in privacy invasions.

The first main way in which the employment of participant observation may give rise to privacy breaches is tied to the participatory aspect of the method. A participating researcher is typically part of, or present in, the situations she studies. Yet simply in virtue of being present, the researcher may violate the privacy of the other participants in a situation: the sheer fact that she participates qua researcher and hence makes observations for research purposes may, independently of the focus of her observations, constitute an intrusion from the perspective of other individuals present in the situation. More precisely, a participant observer invades individuals' situational privacy, as I shall call it, when the following is the case:

- The observing researcher participates in a nonpublic situation without the research participant(s) (or somebody else in authority) having freely granted her access, qua researcher, to the situation.

The central notion in this specification is that of a nonpublic situation. The latter is exemplified by a romantic dinner, a business meeting, a study group assembly, a family gathering, a birthday party, and a reunion of old friends. Nonpublic situations may usefully be contrasted to public situations as illustrated by a concert, a walk in the streets of Copenhagen, a talk show, and standing in line in the supermarket. Whether a situation is categorized as nonpublic or public may vary across time and place. ${ }^{3}$ A social researcher should regard a situation as nonpublic or public depending on how it is classified by the community under study. It goes without saying that it may sometimes be difficult for the participant observer to determine what to count as the community in which the research takes place (e.g. is the relevant community when studying a youth club, its members, young people in general, or the society at large?); how exactly to draw the community's boundaries (e.g. is a religious community to be identified with all its paying members or only with those who regularly go to service?); and what is actually considered as nonpublic and public situations within the community. Likewise, there may be no consensus in a community as to how a situation should be classified. Unfortunately, there is no one-size-fit-all solution to these sorts of difficulties; the participant observer must deal with them on a caseby-case basis.

In light of these considerations, consider the following scenarios: A researcher takes part in closed Alcoholics Anonymous meetings, i.e. meetings where people with a drinking problem share experiences. Another researcher goes to the congregation meetings of her local church. In both cases, the researchers carry out covert participant observation, that is, they do not disclose that they are social researchers "on duty." The first participant observer pretends that she is there because she has a drinking problem; the second that she is religious and wants to take active part in her local church. A third researcher goes to extreme lengths in her attempt to convince a couple to allow her to participate in their everyday life. Finally, the couple gives in and the researcher starts being present when the couple spends time together. In all these scenarios, the participant observer intrudes on the situational privacy of the individuals she studies: she takes part in nonpublic situations without permission or because she has exerted a lot of pressure to be granted access to them.

The second main way in which the employment of participant observation may result in privacy invasions is tied to the observational aspect of the method. When the participating researcher makes

\footnotetext{
${ }^{3}$ This point is in line with a common observation in the literature on privacy to the effect that what is regarded as private varies. See, e.g. Kelman (1977, p. 192); Solove (2008, p. 50ff); Iphofen (2011, p. 102). All the examples I offer should be regarded as compatible with this point: they reflect views on privacy in communities to which I belong.

${ }^{4}$ It is an issue of dispute whether the employment of covert participant observation is sometimes acceptable. Contributions to this discussion include Erikson (1967); Bulmer (1980); Homan (1980); Shils (1980); Bulmer ed. (1982); Macklin (1982); Punch (1986); Miller (1995); Herrera (1999); Lugosi (2006); Calvey (2008); Spicker (2011).
} 
observations, i.e. notices what goes on, she acquires information about the research participants. Yet the collection of certain kinds of information, for research purposes, may constitute a privacy invasion. More precisely, a researcher invades individuals' informational privacy when the following is the case:

- The participating researcher gathers nonpublic personal information by way of observation without the research participant(s) (or somebody else in authority) having freely granted her permission, qua researcher, to do so.

A key notion in this specification is that of personal information. Information of this kind is exemplified by information about a person's health status, financial situation, religious views, love life, and the like. It contrasts with nonpersonal information which concerns, say, a person's hair color, her employment at a university, and her being a dog owner. Personal (and nonpersonal) information may be nonpublic - the other key notion in the above characterization. Nonpublic information is what a person, say, writes in her diary, tells her friend in a tête-à-tête conversation, or relates at a dinner with her closest family. By comparison, public information is in principle available for all to acquire as when a person wears a badge in support of her favorite candidate for presidency, wears paraphernalia that is characteristic of a particular religious affiliation, or offers her opinion on various matters in a television debate. With respect to both these distinctions, viz. personal vs. nonpersonal and nonpublic vs. public information, the manner in which they are drawn may vary across time and place. Similarly to above, a social researcher should regard information as personal or nonpersonal, and as public or nonpublic, depending on how it is classified within the community under study. Accordingly, complications analogous to those registered above may arise concerning what constitutes the relevant community, its exact circumscription, etc. Here too, the participant observer will have to deal with these kinds of issues on a caseby-case basis.

By way of illustration, imagine a social researcher who has been allowed by the members of a reading group to do research on how much and when they read. In reality, though, the participant observer gathers nonpublic information about the members' political outlooks. Also, envisage another researcher who, in conversation, succeeds in coaxing a research participant into divulging details about her sexual preferences and love life. In both these scenarios, the researcher invades the research participants' informational privacy: she acquires nonpublic personal information without permission or as a result of having exerted pressure to be given this information.

It is instructive briefly to consider how the two kinds of privacy intrusion relate to each other. For a start, a participant observer may invade both forms of privacy at the same time. For example, without disclosing that she is carrying out research, she may participate in a nonpublic situation and use this occasion to gather nonpublic personal information. A social researcher may also violate the situational, but not the informational, privacy of those she studies. This happens when she is present, without permission or because she exerted pressure, in a nonpublic situation without collecting any nonpublic personal information. For instance, imagine a couple who profess their love for each other on a talk show. A week later they repeat their vows during a romantic dinner and their exchange is witnessed by a social researcher who has pressured the couple to accept her presence. On this latter occasion, the social researcher violates the couple's situational privacy (a romantic dinner is a nonpublic situation) but not their informational privacy (the couple's love for each other is public personal information). Finally, a social researcher may violate individuals' informational privacy without simultaneously invading their situational privacy. For example, consider a social researcher who has been invited to join a group of research participants for drinks. As the night develops, the researcher finds an opportunity to coerce one of them to talk about her Methodist faith. In this scenario, the participant observer does not violate the group's situational privacy (she was invited to come along). However, she 
breaches the informational privacy of one of its members (the person whom she pressures to talk about her religious views).

The preceding account of situational and informational privacy invasions may briefly be related to current discussions of privacy. Here, privacy is widely described as an interest or concern that individuals have. It is a matter of dispute, however, whether or not individuals' interest in privacy is protected by corresponding rights. My talk about individuals' privacy being invaded, breached, etc. should be regarded as neutral on this issue. For the present purposes, it may be left open whether or not a participant observer's privacy intrusions are wrongs that amount to violations of privacy rights.

In the ongoing debate, a number of different notions of privacy are advocated. One family of approaches is restricted access accounts as defended by, e.g., Ruth Gavison (1980), Anita Allen (1988), and James H. Moor (1990). According to these approaches, the interest in privacy is a concern over others having limited access to one in specified respects. Gavison, for instance, explicates these respects as an individual's interest in others having restricted physical access to her (physical privacy), paying limited attention to her (attentional privacy), and having limited information about her (informational privacy) (Gavison 1980, p. 428). To the extent that others obtain access to an individual in some specified way, restricted access theories maintain, the individual's privacy is in that respect diminished. When this happens the individual may or may not be wronged, that is, the loss of privacy may or may not constitute an invasion, a breach, etc.

My characterization of situational and informational privacy violations is in line with restricted access definitions of privacy. To begin with, the basic idea informing my account may be rephrased as the view that research participants' interest in privacy vis-à-vis a participant observer is first and foremost an interest in the researcher's limited presence in situations that they are also part of (situational privacy) and in her limited acquisition of information about them (informational privacy). Further, the notions of situational and informational privacy invasions may be regarded as specifying under what conditions a participant observer's presence in situations and acquisition of information constitute privacy invasions. The notion of informational privacy is invoked by Gavison and many others. The notion of situational privacy is a development of Gavison's notion of physical privacy. Differently from the idea of physical privacy, the notion of situational privacy is compatible with the recognition that research participants do not only have an interest in the researcher's limited physical presence but also in her limited virtual presence in online settings. More importantly, the notion brings into view that it depends on the situation whether or not the participant observer's presence amounts not only to a diminishment but also to an invasion of the research participants' privacy: it is a function of what activities take place, where they take place, when they take place, the nature of the relationship between those being present if several people are present, and so on. In view of these considerations, the focus on situational privacy is preferable to that of physical privacy. ${ }^{6}$

\footnotetext{
${ }^{5}$ My approach is in agreement with DeCew's. She observes that many points about privacy may be made "independently of whether or not we can ultimately make sense of rights, explain when they are binding, or show they are reducible to utilitarian claims" (DeCew 1997, p. 27). Still, it may be registered, the most common view is probably that individuals have rights to privacy. It is useful to distinguish between moral and legal privacy rights. In the present context, insofar as a participant observer's invasions of research participants' privacy are considered as violations of their privacy rights, these rights should be conceived of as moral rather than legal. Finally note that an issue that has come up in discussions of rights to privacy is whether such rights are derivative from other rights - a view famously defended by Thomson (1975) and criticized by Scanlon (1975). For the present purposes, there is no need to go into this issue.

${ }^{6}$ For discussions of the advantages of restricted access definitions over alternative accounts of privacy, see again Gavison (1980); Allen (1988); Moor (1990). It should be emphasized that the characterization of situational and informational privacy invasions are not necessarily tied to restricted access accounts of privacy. That is, as far as I can see, one or both specifications may well be compatible with alternative definitions of privacy such as control-centered accounts (see, e.g., Westin 1967, p. 7; Fried (1970), p. 140). I consider this a strength of my discussion though I shall not pursue this point here.
} 
Finally, an issue addressed in the general debate on privacy is the value of privacy. Various views have been proposed including that privacy is important because it is crucial for self-development, is conducive to psychological well-being, promotes respect for other people, and is a precondition for the development and maintenance of intimate relationships. ${ }^{7}$ These and other reasons for holding that privacy is important may be used to justify the view that the participant observer should not invade the situational or informational privacy of those she studies. In the present context, it is not necessary to determine exactly why privacy should be regarded as an interest worthy of protection insofar as it is acknowledged that the participant observer may wrongly diminish, i.e. invade, individuals' situational and informational privacy.

\section{The Employment of Informed Consent to Protect Research Participants' Privacy}

There are various, and sometimes overlapping, ways in which to motivate the use of informed consent in a research context. For instance, its employment may be urged on the ground that it supports research participants' autonomy, that it serves to protect research participants from harm, that it ensures that research participants are not deceived, coerced, manipulated, and the like; and that it safeguards their privacy. ${ }^{8} \mathrm{I}$ am exclusively interested in the use of informed consent in its capacity to protect research participants' privacy. In this section, I explicate the principle of informed consent and show how its conditions of application may be specified with a view to safeguarding research participants' situational and informational privacy.

In research in general, informed consent refers to an individual's agreement, prior to the generation of data about her, to be part of a study. At the same time, three conditions must be met: the individual must be competent, informed about the research project, and in a position freely to decide whether to take part in it. If these conditions are not fulfilled, the consent is not valid. The demand that an individual must be competent means that she must be in a position to grasp and reflect on information about a study. For instance, small children are not regarded as competent in this sense and hence their parents or guardians must agree to their enrolment in the research project (or, it is sometimes held, both the children and their parents or guardians must approve of the study). With respect to the requirement that an individual must receive information about a study, there are more or less inclusive views as to what this implies. On a minimal conception, a potential research participant must be told, in a manner comprehensible to her, what the research is about and what will happen to its results, how it will be carried out, and whether the data will be anonymized. Also, it must be conveyed that she is under no pressure to take part in the study and that she may withdraw at any time she pleases. On a more inclusive notion, the individual must also be apprised of the possible risks and benefits from participating in the study, the funding of the project, and the like. The third condition, that an individual must freely agree to participate, means that she must not be pressured or coerced by the researcher to take part in a study. ${ }^{9}$ In light of these considerations, the principle of informed consent may be summarized as the requirement that, prior to the generation of data about her, a competent and informed individual must freely agree to participate in a study.

I shall adopt a permissive notion of informed consent. Accordingly, I shall take it that it is possible to meet the second condition by providing minimal information only and that in many, perhaps most cases, it is enough to obtain an individual's verbal agreement to participate in study; it is not necessary that her

\footnotetext{
${ }^{7}$ See, e.g., Allen (2005, p. 491ff) and Solove (2008, p. 78ff) for an overview of different positions on the value of privacy.

${ }^{8}$ For an overview of different ways in which to justify the use of informed consent, see Eyal (2012). The justification of informed consent as supporting individuals' autonomy is probably the most widespread at least in biomedical research. For a view along these lines, see Faden, Beauchamp, and King (1986). For a discussion of informed consent as protecting against harm, see, e.g. Kelman (1982) and for informed consent as ensuring that research participants are not deceived, coerced, manipulated, and the like, see Manson and O’Neill (2007).

${ }^{9}$ It should be recognized that it is sometimes difficult to determine whether a condition is met and that different views may be entertained in this regard. I shall not go into this complication here.
} 
consent be in writing. Also, I shall assume that the principle requires that an individual must give her informed consent prior to the generation of data specified as data-for-use, that is, data that the researcher may use as evidence and hence refer to (in anonymized form) when reporting her findings. In order to get started, a participant observer often needs to establish contact with potential research participants or gatekeepers, i.e. individuals who have some control over the access to the organization or group that she wants to study. For instance, she may call a potential research participant in order to set up a meeting where she properly informs about her research project and asks the person to agree to take part in it. Or, she may start chatting with a potential research participant about the concert they are both attending and let the conversation run for a while before she explains that she is carrying out a research project and would like the person to consent to become involved in it. The researcher's experiences in these brief initial exchanges may provide her with information that she subsequently draws on in her study. Still, as long as she does not treat this information as data-for-use, its acquisition is compatible with the requirement that the researcher must obtain a research participant's informed consent prior to data collection. Further, I should stress that I see no reason to think of an individual who gives her informed consent as entering into some sort of contractual relationship with the researcher. It is equally possible, and in my view preferable, to conceive of the use of informed consent as a step in the direction of creating a relationship of trust between the social researcher and a research participant. Finally, I shall use the term "informed consent" exclusively to refer to an individual's initial agreement, prior to data generation about her, to take part in study. For the sake of clarity, I want to set apart this first agreement from subsequent occasions on which a research participant indicates her acceptance of some aspect of the research. I discuss the need for such additional agreements in section 6 .

These reflections still leave open an important question, namely the conditions of application of the principle of informed consent. It is exactly through their specification that the principle may be tailored to the safeguarding of research participants' privacy: it may be maintained that an individual's informed consent to participate in a study must be obtained whenever the research project is likely to make it relevant for the social researcher a) to participate in situations that involve the individual while being regarded as nonpublic by the individual's community or b) to gather, by way observation, information that is about the individual and that is nonpublic and personal according to the individual's community. ${ }^{10}$ In virtue of this specification, the principle serves a privacy protecting function: when informing an individual about her project, the participant observer conveys an idea of the nonpublic situations and the nonpublic personal information that she would like to access. Consequently, if the individual agrees to be part of the study, she also permits the researcher to access these situations and this information. It may be added that insofar as the researcher does not plan either to access nonpublic situations or to gather nonpublic personal information when carrying out participant observation, she does not need to ask individuals for their informed consent.

I shall henceforth assume that the participant observer should indeed subscribe to the principle of informed consent supplemented by these conditions of application. This contention raises two important issues. Should the principle be embraced as an absolute demand or is it sometimes permissible to take exception to the principle and hereby set to a side the privacy protection it offers? And does adherence to the principle ensure that research participants' situational or informational privacy is not invaded or is it now and then necessary to take further measures to this end? In the next two sections, I discuss these questions in turn.

\footnotetext{
${ }^{10}$ During the planning phase of a research project, the researcher typically acquires a rough idea of some of the situations and information that she would like to access as part of her study. Yet it may well be that she has no clear picture of whether the community she wants to study regards these situations as nonpublic and this information as nonpublic personal information. In that case, the researcher must find this out (on different ways in which to approach this task, see Sieber 1992, pp. 40-50).
} 


\section{Is the Principle of Informed Consent an Absolute Principle?}

In the literature on participant observation and qualitative research more generally, it is a matter of dispute whether an exception to the principle of informed consent is sometimes justified. ${ }^{11}$ In this section, I examine what I take to be the most convincing line of reasoning against the principle as an absolute demand while adapting the argumentation to the present focus on the protection of research participants' situational and informational privacy. I argue that, properly developed, the argument succeeds.

Consider the following claims:

1) Sometimes it is not doable to ask individuals to give their informed consent to a study that requires access to nonpublic situations or nonpublic personal information. Maurice Punch points to two reasons for this (Punch 1986). One is that sometimes "gaining consent is quite inappropriate, because activity is taking place that cannot be interrupted" (ibid. 36). As an illustration, Punch asks the reader to picture a participant observer who is out on patrol with two policemen. The latter see a street fight that they then try to stop. Here, Punch contends, the social researcher cannot ask the troublemakers to take a break from fighting in order to try to obtain their informed consent. While a street fight is not a nonpublic situation, there are likely to be many nonpublic situations in which it is likewise inappropriate to interfere in order to gain people's informed consent. The other reason is that it may not be practically feasible to ask everybody at a research site for their informed consent. Punch refers to his own study of the police when exemplifying this point: "[i]n a large organization [like the police], engaged in constant interaction with considerable numbers of clients (including ordinary members of the public, victims, criminals, people in distress, etc.), it is [...] physically impossible to inform everyone of one's purpose and identity" (ibid.).

2) Certain groups tend to refuse participation in research projects that involve access to nonpublic situations and nonpublic personal information. For instance, Albert Reiss reports a study in which upper class individuals tended to decline participation to a much higher degree than lower class individuals (Reiss 1979, p. 77). More generally, Reiss suggests, powerful and high status people seem more prone to refuse participation in studies.

These claims point to circumstances in which the participant observer is unable to secure some or all of the research participants' informed consent. In this manner, the claims bring into view - and exemplify - that there are occasions where adherence to the principle of informed consent, as an absolute principle, precludes the production of scientific knowledge about a certain type of activity, setting, or group. One possible response to this observation is that this is just too bad. Another is that an exception to the principle of informed consent is sometimes in order. The most convincing objection to the principle, as an absolute demand, implicitly or explicitly defends this latter line of approach by appeal to the view that the acquisition of scientific knowledge about a certain type of activity, setting, group, or the like is sometimes so important that it outweighs the value of respecting individuals' situational and informational privacy. On these occasions, it is held, it is acceptable to set to a side the principle of informed consent.

In my view, this argument is on the right track: exceptions are sometimes in order. However, as it stands the reasoning is incomplete insofar as it fails carefully to spell out all the conditions that must be met in order to warrant an exception to the principle of informed consent. It is not enough that a participant observer simply contends that her research project will produce highly valuable knowledge worth the cost of not obtaining some or all of the research participants' informed consent. She must go over the following conditions and be prepared to defend that they are fulfilled in relation to her study:

\footnotetext{
${ }^{11}$ For discussions pertaining to this issue, see, e.g., Erikson (1967); Bulmer (1980); Homan (1980); Shils (1980); Bulmer ed. (1982); Macklin (1982); Punch (1986); Fluehr-Lobban (1994); Miller (1995); Herrera (1999); Lugosi (2006); Calvey (2008); Spicker (2011); Fluehr-Lobban (2013).
} 
The first condition is that the use of informed consent, while carrying out participant observation, does indeed prevent the acquisition of scientific knowledge about a certain type of activity, setting, etc. The researcher must have reasons in support of this claim. This means that if she appeals to 1), say, she must have grounds for thinking that while carrying out participant observation she may not somehow overcome the practical obstacles to asking individuals to give their informed consent. Or if she invokes 2), she must have considered a number of ways of approaching the group in question while arriving at the conclusion that no matter how, too few or none of the group members will give their informed consent to her carrying out participant observation.

The second condition is that the employment of informed consent, in combination with some other data gathering method, likewise rules out the production of scientific knowledge about the type of activity, setting, etc. For instance, assume that the researcher is convinced that she will encounter the obstacle described in 2) if asking permission to carry out participant observation. In this case, she should also have a good basis for holding that she might not instead obtain the data she needs for her study by interviewing people after having obtained their informed consent without difficulty. Fulfilling both condition 1 and 2 shows that there is no way of acquiring knowledge about the type of activity, setting, etc. that is compatible with abidance to the principle of informed consent as an absolute demand.

The third condition is that obtaining knowledge about the type of activity, setting, etc. is valuable to such an extent that this outweighs the importance of respecting research participants' situational and informational privacy. In order to fulfill this condition, the researcher must reflect on why it is important to gain the knowledge. Also, she should determine the graveness, according to the community she plans to study, of the privacy intrusions that will likely follow from her study. In this community, her participation in some nonpublic situations will probably be regarded as more of an intrusion, i.e. a graver privacy invasion, than her presence in others and, mutatis mutandis, the same goes for nonpublic personal information. On this basis, she may then settle on the view that the value of acquiring scientific knowledge about the type of activity, settings, etc. overrides the concern with not invading individuals' privacy. Obviously, the more important the knowledge and the less grave the privacy violations, the easier it is to meet this third condition, and vice versa.

Only insofar as all three conditions are fulfilled is an exception to the principle of informed consent justified relative to some or all of the research participants in a particular research project. ${ }^{12}$ It is clear that the task of making - and defending - the judgments necessary to claim that all three conditions are met may sometimes be a demanding one. Unfortunately, there is no way around this predicament: the participant observer will have to deal with these difficulties At the same time, it is worth stressing, there are also many instances where it will be rather straightforward to make these sorts of judgments. I am inclined to think that the importance of producing scientific knowledge about some type of activity, setting, etc. may only exceed the value of protecting individuals' privacy in cases when carrying out participant observation results in privacy invasions that are not grave. When only minor privacy breaches occur, I believe that participant observers will not have any special difficulties in fulfilling the third condition. These views, though, are not ones that I shall defend here. The important point of the discussion is that there are conditions such that if they are met, a

\footnotetext{
${ }^{12}$ Note that I am only saying that these three conditions must be met when using informed consent to protect the privacy of those under study. Informed consent may serve other purposes and relative to these it may be that additional conditions must be met in order to take exception to the principle. Further note that I am taking it that informed consent is the only form of consent that may serve to protect individuals' privacy. Rejecting this view would not affect my conclusion. To see this, assume that passive consent, i.e. individuals are taken to agree to a study unless they actively refuse participation, is said sometimes to be equally effective in protecting research participants' privacy. In that case, it will also be acceptable to take exception to the principle of informed consent whenever passive consent might equally well be employed to protect individuals' privacy. Or assume that passive consent is said to be effective, though less so, in safeguarding individuals' privacy. Then it will be easier to meet the third condition: whenever passive consent may be used, the privacy breaches will be less grave than they would otherwise be and hence there are likely to be more cases in which the value of acquiring the scientific knowledge will supersede the value of respecting individuals' privacy.
} 
social researcher is justified in making an exception to the principle of informed consent when carrying out participant observation. The principle is not an absolute demand.

\section{Does Adherence to the Principle of Informed Consent Suffice?}

The fact that the principle of informed consent has exceptions leaves it open whether it suffices to protect research participants' situational and informational privacy: Is it the case that if the participant observer obtains individuals' informed consent, then she may rest assured that their situational and informational privacy is not invaded while she collects data about them? Below I point to three circumstances in which the principle is not up to the task of preventing such violations. I do not claim that these circumstances are necessarily the only occasions on which informed consent fails to safeguard individuals' privacy, or that one or the other circumstance may not arise in connection with other data gathering methods. My contention is merely that these circumstances frequently occur when carrying out participant observation. It has been pointed out before that it is not enough to obtain individuals' informed consent prior to the commencement of data collection (see, e.g. Wax 1980). Still, so far no systematic discussion has been offered of the exact circumstances in which informed consent falls short to prevent breaches of research participants' privacy while participant observation is carried out.

The first circumstance is related to a feature of participant observation as it is typically employed: commonly, the initial research question, formulated by the researcher prior to the onset of data collection, is modified while she carries out participant observation. The research question is typically made more precise as the generation of data progresses, but it may also be modified in other ways, or be discarded in favor of a different research question (see, e.g. Hammersley and Atkinson 2003, p. 24). Insofar as the participant observer changes her question in other ways than by rendering it more precise, she violates research participants' situational and informational privacy if she participates in nonpublic situations or gathers nonpublic personal information in order to shed light on this new question. The reason is, of course, that the new project was not what the research participants agreed to. To prevent such breaches, the social researcher needs to inform the research participants about her changed research plans and to obtain their acceptance of the new purpose of her research.

The second circumstance occurs because research participants' informed consent often underdetermines what nonpublic situations and nonpublic personal knowledge that fall within its scope. This idea needs some unpacking. When a participant observer provides information about her research project to a prospective research participant, she keeps it in very general terms. For instance, she may explain that she is interested in the role religion plays in everyday life, in the way health visitor training is done, or in ways of handling the financial crisis. Even though a social researcher may elaborate further on the purpose of her research, she will never, as part of this, provide a complete enumeration of all the nonpublic situations and nonpublic personal information that it is relevant for her to access. As the method of participant observation is commonly employed, the social researcher has only a rough idea of what data to gather prior to the onset of data collection. Most decisions to this effect are made as she goes along carrying out participant observation. By implication, when she asks individuals to give their informed consent, the participant observer does typically not have any fixed and clear idea of all the kinds of nonpublic situations and nonpublic personal information that may be of interest to her. This being the case, the information she provides about the purpose of her research is bound to be kept in general terms.

In many cases this is unproblematic: it is obvious whether a nonpublic situation or some nonpublic personal information falls within the scope of a research project as described in connection with obtaining an individual's informed consent. Yet there are also times when it is less obvious; in these cases, I shall say, the informed consent underdetermines what nonpublic situations and nonpublic personal 
information it covers. As an illustration of this point, consider a group of nursing students who agree to participate in a study on "becoming a nurse." Here, the sessions in which the nursing students receive instruction and exchange information pertaining to their nursing education obviously fall within the scope of the students' consent to the research project. At the same time, it is less obvious that the students' conversations, outside class, concerning their leisure activities, family situations, and living conditions are covered by their consent. Or contemplate the members of a soccer club who give their informed consent to be part of a study of the social life in their club. The researcher hanging around in the soccer club obviously falls within the scope of the informed consent. But what if one of the members invites his team and the coaches home for his birthday? This is an occasion that is less obviously covered by the informed consent. Admittedly, it may sometimes be difficult to determine what obviously and less obviously falls within the scope of an informed consent. Still, the basic idea informing this distinction between what is obviously and less obviously covered should be fairly clear and for the present purposes this suffices. ${ }^{13}$

The point is now that when research participants' informed consent underdetermines whether a nonpublic situation and some nonpublic personal information fall within its scope, it should be up to them to determine this: it constitutes a specification of what they are willing to consent to. Accordingly, if the social researcher simply goes ahead and participates in such a situation or acquires such information, she risks invading the research participants' situational or informational privacy because these may ascertain that the situation or information should be regarded as falling outside the scope of the informed consent. Therefore, whenever a nonpublic situation or some nonpublic personal information is not obviously covered by the research participants' informed consent, the social researcher should only participate in the situation or acquire the information if they indicate their acceptance of it. Sometimes research participants may spontaneously express their approval or disapproval; other times the participant observer may have to prompt them to express it. Moreover, research participants need not express their approval or disapproval verbally, just as the researcher does not have explicitly to raise the issue with them: a research participant may indicate her acceptance, say, by nodding, by smiling, by holding the door for the participant observer, or by not opposing the social researcher's presence or information gathering. Similarly, the social researcher may make it clear that she is waiting for a research participant's acceptance by, say, sending her a questioning look, by staying in the background, or by looking down. In this fashion, the social researcher's figuring out what the research participants are willing to regard as falling within the scope of their informed consent need not be in any way disruptive of ongoing activities. It requires, though, a certain measure of social sensitivity on the part of the social researcher: she must be able to pick up on the research participants' indications of approval or disapproval. In a discussion of her study of young offenders in secure care institutions, Tea Bengtsson provides an example that nicely exemplifies the gist of these considerations: "if I entered a room, and the young people all fell silent," she writes, "I would quickly leave in an attempt to respect their privacy" (Bengtsson 2014, p. 732).

Concerning the extent to which a social researcher is likely to be granted access to situations and information that do not obviously fall within the scope of research participants' informed consent, it is worth remembering that participant observation is typically carried out over an extended period of time. Moreover, the social researcher's relationships with research participants "are not governed solely by a formalised, relatively standardised research role" (Hammersley and Traianou 2012, p. 106). In fact, their interactions are often quite informal: the social researcher participates in, and tries to some degree to blend into, the research participants' ways of life. As a result, research participants get to know, or grow used to, the social researcher

\footnotetext{
${ }^{13}$ In order for informed consent to prevent breaches of research participants' privacy, the social researcher and the research participants must share roughly the same understanding of the scope of the informed consent, that is, of what is obviously, less obviously, and not at all covered by it. For the sake of simplicity, I am disregarding cases in which this sort of common understanding is lacking.
} 
just as friendly relations or even friendships commonly develop. The more the research participants get to trust the participant observer, the more she is granted access to nonpublic situations and nonpublic personal information that do not obviously fall within the scope of the informed consent. This is one of the great strengths of the method of participant observation. At the same time, this is also what paves the way for the third type of circumstance in which the use of informed consent does not suffice to protect research participants' privacy.

Insofar as research participants become accustomed to or form a relationship with the social researcher, they may sometimes assume that the social researcher is only present, say, in her capacity of friend, as one of the team, or as the person who just hangs around; they may fail to recognize that she is also participating and making observations for research purposes. The literature on participant observation is ripe with examples of situations in which the researcher is convinced, or suspects, that the research participants do not take it that research is also being carried out. Here are for example Judith Hansen's reflections on this sort of circumstance in relation to her fieldwork in Denmark: "Would she have spoken so frankly about this or other more intimate subjects had she understood that I listened in both roles, not only as a friend? True, I had said that I was an anthropologist [...] but as we began to relate on a human to human basis rather than merely as American visitor to native Dane, this ceased to be an active factor in people's perception of our interaction and they talked to me as a friend that would respect the confidences they shared with me" (Hansen 1976, p. 129).

A participant observer invades the privacy of the individuals under study insofar as they accept her participation in a nonpublic situation or provide her with nonpublic personal information because they are wrongly, but quite reasonably, under the impression that, on the occasion, she is not carrying out participant observation. ${ }^{14}$ To avoid such invasions, the social researcher may take preventive measures in the sense of reminding people, or making it clear to them, that she is present in her role as researcher too. In this spirit, Kathleen DeWalt and Billie DeWalt comment that "the researcher should occasionally remind people of the research nature of the relationships. Taking notes in public at least some of time may be a way to do this" (DeWalt and DeWalt 2011, p. 217). Another way in which to remind people may be casually to bring this up in conversation. In this approach to the prevention of privacy invasions, the social researcher makes sure that the research participants are actually aware that she is generating data. An alternative strategy consists in the participant observer asking the research participants whether they take it, and find it acceptable, that she carries out participant observation on some occasion. If they reply that this is fine, she may go ahead and make observations for research purposes. If they say that it's not fine with them, she should regard herself as present in her capacity as, say, friend only. Anne Ryen exemplifies this line of approach when she writes that "[s]ome (high-status) informants have differentiated between information given me as a friend as opposed to data for my research expressed as 'This is only for you, not for your research.' If I have been in doubt, I have simply asked them” (Ryen 2004, p. 22).

In light of these reflections, it may be concluded that in three common circumstances, the employment of informed consent does not suffice to protect research participants' situational and informational privacy. On these occasions, the participant observer must take the supplementary measures described above in order to prevent privacy breaches from occurring.

\footnotetext{
${ }^{14}$ For a discussion of these situations as giving rise to privacy invasions, see also, e.g., Kelman (1977, p. 180ff) and Hammersley and Traianou (2012, p. 106ff).
} 


\section{Conclusion}

In this paper, I have examined the proposal that social researchers should abide by the principle of informed consent in order to protect research participants' privacy while carrying out participant observation. After a brief introduction to the method, I outlined two main ways in which the social researcher may breach people's privacy when carrying out participant observation: she may violate their situational and informational privacy. Next I showed how the principle of informed may be specified such as to serve to protect individuals from such invasions. On that basis, I moved on to establish two points: I showed that the principle should not be regarded as an absolute demand: under specified conditions, it is justifiable to take exception to it. And I demonstrated that, in three common circumstances, informed consent does not suffice to protect research participants' situational and informational privacy. Accordingly, the participant observer needs to take a number of supplementary measures in order to prevent privacy invasions from occurring.

By way of ending, it is worth reiterating that adherence to the principle of informed consent may serve other purposes than protecting individuals' privacy. Also, there are of course other principles and considerations that a participant observer should take into account in order to ensure that she acts in ethically acceptable ways towards those she studies. These points raise issues deserving future scrutiny as to the way in which to combine the protection of research participants' privacy with a concern for other ethical values, principles and considerations. ${ }^{15}$

\section{References}

Agar, Michael H. 1980. The Professional Stranger. An Informal Introduction to Ethnography. Orlando: Academic Press. Inc.

Allen, Anita L. 1988. Uneasy Access. Privacy for Women in a Free Society. New Jersey: Rowman \& Littlefield. Allen, Anita L. 2005. "Privacy." Pp. 485-513 in The Oxford Handbook of Practical Ethics. Edited by Hugh LaFollette. Oxford: Oxford University Press.

Bailey, Carol A. 1996. A Guide to Field Research. Thousand Oaks: Pine Forge Press.

Bengtsson, Tea T. 2014. "What are data? Ethnographic experiences with young offenders." Qualitative Research 14(6): 729-744.

Bulmer, Martin 1980. "Comment on 'The Ethics of Covert Methods'." The British Journal of Sociology 31(1): 59-65.

Bulmer, Martin ed. 1982. Social Research Ethics: An Examination of the Merits of Covert Participant Observation. London: Macmillan.

Calvey, David 2008. "The Art and Politics of Covert Research: Doing 'Situated Ethics' in the Field." Sociology 42(5): 905-918.

Christians, Clifford G. 2011. "Ethics and Politics in Qualitative Research." Pp. 61-80 in SAGE Handbook of Qualitative Research. Edited by Norman K. Denzin and Yvonna S. Lincoln. Los Angeles: SAGE Publications.

\footnotetext{
${ }^{15}$ The research for this paper was funded by the University of Copenhagen's Excellence Programme for Interdisciplinary Research as part of the interdisciplinary research project "Social Fabric." I would like to thank Klemens Kappel and two anonymous referees for their helpful comments. Also, I have presented the paper at the workshop "Research Ethics and Social Inquiry," University of Copenhagen, Denmark (fall 2014); at the "Philosophy of Science (PoS) Seminar," Finnish Centre of Excellence in the Philosophy of the Social Sciences, University of Helsinki, Finland (spring 2015); at the workshop "Current Topics in Philosophy of the Social Sciences," University of Washington, Seattle, USA (spring 2015); and at the "Society for Philosophy of Science in Practice (SPSP) Fifth Biennial Conference," University of Aarhus, Denmark (summer 2015). I have benefitted from the suggestions made by the audiences on all these occasions.
} 
DeCew, Judith W. 1997. In Pursuit of Privacy: Law, Ethics, and the Rise of Technology. Ithaca: Cornell University Press.

DeWalt, Kathleen M. and Billie R. DeWalt. 2011. Participant Observation. A Guide for Fieldworkers. Lanham: Altamira Press.

Erikson, Kai T. 1967. "A Comment on Disguised Observation in Sociology.” Social Problems 14(4): 366-373.

Eyal, Nir. 2012. "Informed Consent." See http:/plato.stanford.edu/archives/fall2012/entries/informed-consent/ in The Stanford Encyclopedia of Philosophy. Edited by Edward N. Zalta.

Faden, Ruth R., Thomas L. Beauchamp, and Nancy M. King. 1986. A History and Theory of Informed Consent. New York: Oxford University Press.

Fluehr-Lobban, Carolyn. 1994. "Informed Consent in Anthropological Research: We are not Exempt." Human Organization 53(1): 1-10.

Fluehr-Lobban, Carolyn. 2013. Ethics and Anthropology. Ideas and Practice. Lanham: Altamira Press.

Fried, Charles. 1970. An Anatomy of Values. Cambridge, Mass.: Harvard University Press.

Gavison, Ruth. 1980. "Privacy and the Limits of Law." The Yale Law Journal, 89(3): 421-471.

Gold, Raymond L. 1969. "Roles in sociological field observations." Pp. $30-39$ in Issues in Participant Observation. Edited by George J. McCall and J.L. Simmons. Reading, MA: Addison-Wesley Publishing Company.

Hammersley, Martyn and Paul Atkinson. 2003. Ethnography. London: Routledge.

Hammersley, Martyn and Anna Traianou. 2012. Ethics in Qualitative Research: Controversies and Contexts. London: SAGE Publications.

Hansen, Judith F. 1976. "The anthropologist in the field: Scientist, friend, voyeur." Pp. 123-134 in Ethics and anthropology: Dilemmas in fieldwork. Edited by Michael A. Rynkiewich and James P. Spradley. New York: Wiley.

Herrera, Chris D. 1999. "Two arguments for 'covert methods' in social research.” British Journal of Sociology 50(2): 331-343.

Homan, Roger 1980. "The ethics of covert methods." British Journal of Sociology 31(1): 46-59.

Iphofen, Ron. 2011. Ethical Decision-Making in Social Research. Basingstoke: Palgrave Macmillan.

Jorgensen, Danny L. 1989. Participant Observation. Newbury Park, CA: Sage Publications.

Kelman, Herbert C. 1977. "Privacy and Research with Human Beings." Journal of Social Issues 33(3): 169195.

Kelman, Herbert C. 1982. "Ethical Issues in Different Social Science Methods." Pp. 40-98 in Ethical Issues in Social Science Research. Edited by Tom L. Beauchamp, Ruth R. Faden, R. Jay Wallace Jr., and LeRoy Walters. Baltimore: The John Hopkins University Press.

Lugosi, Peter. 2006. "Between Overt and Covert Research: Concealment and Disclosure in an Ethnographic Study of Commercial Hospitality." Qualitative Enquiry 12(3): 541-561.

Macklin, Ruth. 1982. "The Problem of Adequate Disclosure in Social Science Research.” Pp. 193-214 in Ethical Issues in Social Science Research. Edited by Tom L. Beauchamp, Ruth R. Faden, R. Jay Wallace Jr., and LeRoy Walters. Baltimore: The John Hopkins University Press.

Malinowski, Bronislaw. 1922. Argonauts of the Western Pacific. London: George Routledge and Sons, Ltd.

Manson, Neil C., and Onora O’Neill. 2007. Rethinking Informed Consent in Bioethics. Cambridge: Cambridge University Press.

Miller, Mitch. 1995. "Covert Participant Observation: Reconsidering The Least Used Method.” Journal of Contemporary Criminal Justice 11(2): 97-105.

Moor, James H. 1990. “The Ethics of Privacy Protection.” Library Trends 39(1 \& 2): 69-82.

Nelson, Richard K. 1986. Hunters of the Northern Forest. Chicago, IL: University of Chicago Press.

Punch, Maurice 1986. The Politics and Ethics of Fieldwork. Beverly Hills, CA: Sage. 
Reiss, Albert J. 1979. "Governmental Regulation of Scientific Inquiry: Some Paradoxical Consequences.” Pp. 61-95 in Deviance and Decency. The Ethics of Research with Human Subjects. Edited by Carl B. Klockars and Finbarr W. O'Connor. Beverly Hills: Sage Publications.

Ryen, Anne 2004. "Ethical Issues.” Pp. 218-235 in Qualitative Research Practice. Edited by Clive Seal, Giampietro Gobo, Jaber F. Gubrium and David Silverman. Los Angeles: Sage.

Scanlon, Thomas. 1975. "Thomson on Privacy." Philosophy and Public Affairs 4(4): 315-322.

Shils, Edward. 1980. The Calling of Sociology and Others Essays on the Pursuit of Learning. Chicago: University of Chicago Press.

Sieber, Joan E. 1992. Planning Ethically Responsible Research. Newbury Park: SAGE Publications, Inc.

Solove, Daniel J. 2008. Understanding Privacy. Cambridge, MA: Harvard University Press.

Spicker, Paul. 2011. "Ethical Covert Research.” Sociology (45(1): 118-133.

Spradley, James P. 1980. Participant Observation. Fort Worth: Harcourt Brace Jovanovich College Publishers. Thomson, Judith J. 1975. "The Right to Privacy.” Philosophy of Public Affairs 4(4): 295-314.

Wax, Murray L. 1980. "Paradoxes of 'Consent' to the Practice of Fieldwork." Social Problems. 27(3): 272-283.

Westin, Alan F. 1967. Privacy and Freedom. New York: Atheneum.

Zahle, Julie. 2012. "Practical Knowledge and Participant Observation.” Inquiry 55(1): 50-65.

Zahle, Julie. 2016. "Methodological Anti-Naturalism, Norms and Participant Observation." Pp. 78-95 in Normativity and Naturalism in the Philosophy of the Social Sciences. Edited by Mark Risjord. London: Routledge. 